\title{
Investigation on heat-transfer-coefficient between aluminum alloy and organic/inorganic sand mold based on inverse method
}

\author{
*Jing-ying Sun ${ }^{1}$, Qi-chi Le', Tong Wang' ${ }^{1}$ Xu Zhao', Wei-sen Shi ${ }^{2}$, Hong-wei Huo ${ }^{2}$, and Chiri Wang ${ }^{3}$ \\ 1. Key Laboratory of Electromagnetic Processing of Materials, Ministry of Education, Northeastern University, Shenyang 110819, China \\ 2. BMW Brilliance Automotive Ltd., Shenyang 100044, China \\ 3. ASK Chemicals (Zhenjiang) New Materials Technology Co, Ltd., Shanghai 200032, China
}

\begin{abstract}
A kind of cylinder sand mold was designed to investigate the heat-transfer-coefficients (HTCs) between aluminum alloy and organic/inorganic binder bonded sand mold during the solidification processes. Temperature during the solidification process was recorded and input into the simulation software. The inverse model of MAGMA was used to calculate the HTC based on the actual temperature. Results show that the temperature of the inorganic sand mold increased faster than the organic sand mold; while the temperature of the casting part with the inorganic sand mold decreased faster. The optimal HTCs between Al and the organic/ inorganic sand mold are confirmed to be 300 to 700 and 1000 to $1800 \mathrm{~W} \cdot \mathrm{m}^{-2} \cdot \mathrm{K}^{-1}$, respectively, along with the change of solid-liquid phase line. The simulated temperature curves show the same trend as the measured ones. The maximum deviation between the two temperature curves are $17.32^{\circ} \mathrm{C}$ and $18.77^{\circ} \mathrm{C}$ for castings by inorganic and organic sand molds.
\end{abstract}

Key words: heat-transfer-coefficient; aluminum alloy; organic; inorganic; inverse method

CLC numbers: TG221 Document code: A

Article ID: 1672-6421(2019)05-336-06

$\mathrm{W}$ ith the continuous development of computer simulation technology, improving the accuracy of casting simulation process has become a critical challenge for many researchers that needs to be overcome ${ }^{[1]}$. In order to improve the accuracy of casting simulation, the change of HTC, which is one of the most important boundary conditions during the solidification process, must be known. Many researchers propose that the inverse method is a highly efficient way of calculating HTC ${ }^{[2-4]}$. Based on the inverse method, the HTC value of the permanent-mold casting of Ti- $6 \mathrm{Al}-4 \mathrm{~V}$ was found to decrease linearly from 2,000 to $1,500 \mathrm{~W} \cdot \mathrm{m}^{-2} \cdot \mathrm{K}^{-1}$ between the liquidus and the solidus ${ }^{[5]}$. The HTC of the squeeze casting of AM60 magnesium alloy was also investigated by extrapolation and numerical inverse methods, and the results indicated that the heat flux and the HTCs determined by the inverse method were more accurate than by the extrapolated fitting method ${ }^{[6]}$. Recently, Zhang $\mathrm{A}^{[7]}$ studied the HTC between aluminum alloy and

\section{*Jing-ying Sun}

Male, born in 1990, Ph.D. Research interests: aluminum alloy low pressure die casting process and simulation.

E-mail: sunnyfish1990@126.com

Received: 2019-05-20; Accepted: 2019-08-06 the sand mold in the low-pressure sand casting. Results showed that the accuracy of HTC calculated using the inverse method was increased by $50 \%$ if the temperature dependence of the thermo-physical parameters was considered, rather than the normal constant treatment or simple linear interpolation versus temperature.

With higher requirement of energy saving and environmental protection, the traditional organic sand cores are replaced by inorganic ones with a lower carbon emission. More and more inorganic binder bonded sand cores are gradually being used to produce complex castings ${ }^{[8]}$. However, the difference of the heat-transfer behavior and HTC values between organic and inorganic sand molds is not clear. In order to ensure the accuracy of simulation, the difference of HTC values between organic and inorganic sand mold castings needs to be clarified.

In this study, the temperature changes of the A356 aluminum alloy in organic and inorganic sand molds were measured during the solidification processes. Based on the inverse method, the HTC values of the A356 aluminum alloy with organic and inorganic sand molds were also calculated. To verify the accuracy of the calculation, the experimental temperature curves, shrinkage morphologies and secondary dendrite arm 
spacing (SDAS) of the organic and inorganic sand castings were compared with the simulation results.

\section{Experimental procedure}

K-type thermocouples (TC) were used to measure the temperature of the casting and mold. Phoenix TM 10-channels temperature recorder was used to record the temperature every second for 1800 seconds. In order to ensure the accuracy of temperature measurement and simplify the inverse calculation model, a cylinder sand mold was designed. The mold and the layout of the TCs are shown in Fig. 1. TC1 and TC2 were used to measure the temperature of the casting and mold, respectively. The positions of the thermocouples should be as close as possible to the interface of the casting and mold.

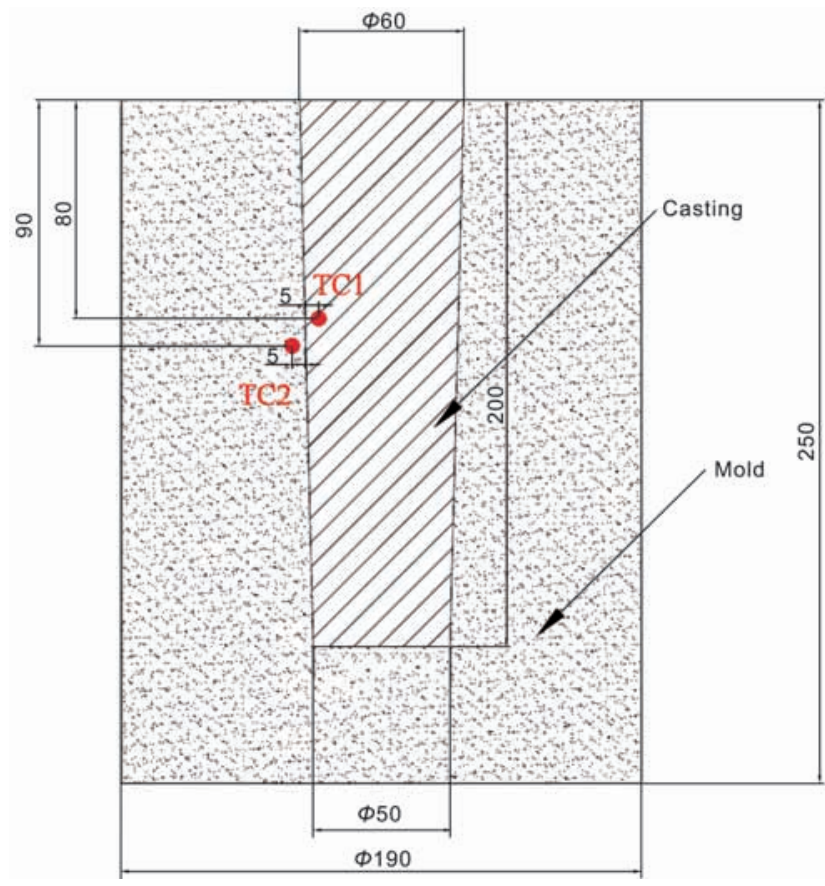

Fig. 1: Experimental layout of mold and thermocouples

The chemical compositions of the A356 aluminum alloy are shown in Table 1 . The solidus and liquidus are $542{ }^{\circ} \mathrm{C}$ and $613{ }^{\circ} \mathrm{C}$, respectively. The thermophysical parameters of the aluminum alloy and different sand molds are shown in Fig. 2. The pouring temperature is $700{ }^{\circ} \mathrm{C}$, and sand molds were preheated to $50^{\circ} \mathrm{C}$. Finally, the castings were cut longitudinally from the middle section to compare the shrinkage morphologies with simulation results. The microstructure was observed by an optical microscope and the SDAS was measured to evaluate the cooling rate of the castings by organic and inorganic sand molds. Three values were achieved in each area, and the average values were used for comparison.

Table 1: Chemical compositions of A356 alloy studied (wt.\%)

$\begin{array}{ccccccc}\text { Si } & \text { Mg } & \text { Zn } & \text { Mn } & \text { Sr } & \text { Fe } & \text { Al } \\ 7.23 & 0.36 & 0.007 & 0.0139 & 0.008 & 0.12 & \text { Bal. }\end{array}$

\section{Inverse method}

The inverse method was carried out to solve the HTC between the casting and the sand mold. In order to make the program run continuously and achieve the required solution accuracy, the convergence criterion must be established. According to the characteristics of the inverse method for HTC calculation, the temperature deviation between the measured temperature and the calculated temperature by each iteration is used as the convergence criterion. The convergence criterion is as follows:

$$
S(h)=\sum_{i=1}^{N_{t}} \sum_{j=1}^{N_{m}} \frac{1}{\sigma_{T}^{2}}\left[T_{i j}^{m}-T_{i j}^{c}(h)\right]^{2}+\sum_{k=1}^{N_{h}} \frac{1}{\sigma_{k}^{2}}\left[h_{k}-h_{k}^{0}\right]^{2}
$$

where $T_{i j}^{m}$ is the measured temperature of the measured points $x_{j}\left(j=1, \ldots, N_{m}\right)$ change with the time, $t_{\mathrm{i}}\left(i=1, \ldots, N_{t}\right) ; T_{i j}^{c}(h)$ is the calculated temperature accordingly; $h=\left\{h_{1}, h_{2}, \cdots, h_{N_{h}}\right\}$ is the unknown HTC; $N_{m}$ is the number of thermocouples for temperature measurement; $N_{t}$ is the number of time points; $N_{h}$ is the number of calculate HTC; $\sigma_{T}$ is the error of measured temperature; $\sigma_{k}$ is the maximum allowable change in each iteration; $h_{k}^{0}$ is the initial HTC.

When $S(h)$ is minimized, $h$ can be obtained. Take derivatives on both sides:

$$
\frac{\partial S}{\partial h_{1}}=\sum_{i=1}^{N_{t}} \sum_{j=1}^{N_{m}} \frac{(-2)}{\sigma_{T}^{2}}\left[T_{i j}^{m}-T_{i j}^{c}(h)\right] \cdot X_{i j l}+\frac{2}{\sigma_{l}^{2}}\left[h_{l}-h_{l}^{0}\right]=0
$$

where $X_{i j l}$ is the sensitive coefficient, and $X_{i j l}$ is expanded by Taylor formula at $h_{l}$ position:

$$
\begin{aligned}
& X_{i j l}=\frac{\partial T_{i j}^{c}(h)}{\partial h_{1}} \\
& \cong \frac{T_{i j}^{c}\left(h_{1}, \cdots, h_{l}+\delta h_{l}, \cdots h_{N_{h}}\right)-T_{i j}^{c}\left(h_{1}, \cdots, h_{l}, \cdots, h_{N_{h}}\right)}{\delta h_{1}}
\end{aligned}
$$

Where $\delta h_{l}$ is the change of the previous iteration $h_{l}$, and it is used for calculating the sensitive coefficient. During the temperature calculating process, the next iterative temperature $T_{i j}^{c}\left(h^{v+1}\right)$ will also be linearized:

$$
T_{i j}^{c}\left(h^{v+1}\right) \cong T_{i j}^{c}\left(h^{v}\right)+\sum_{k=1}^{N_{h}} X_{i j k}^{v} \cdot \Delta h_{k}
$$

In the formula, the variation of the HTC $\Delta h_{k}$ will be achieved by the following equation:

$$
\begin{gathered}
\sum_{k=1}^{N_{h}} A_{l k} \cdot \Delta h_{k}=f_{l} \\
A_{l k}=\sum_{i=1}^{N_{t}} \sum_{j=1}^{N_{m}} \frac{X_{i j k} \cdot X_{i j l}}{\sigma_{T}^{2}}+\frac{\delta_{l k}}{\sigma_{l}^{2}}
\end{gathered}
$$



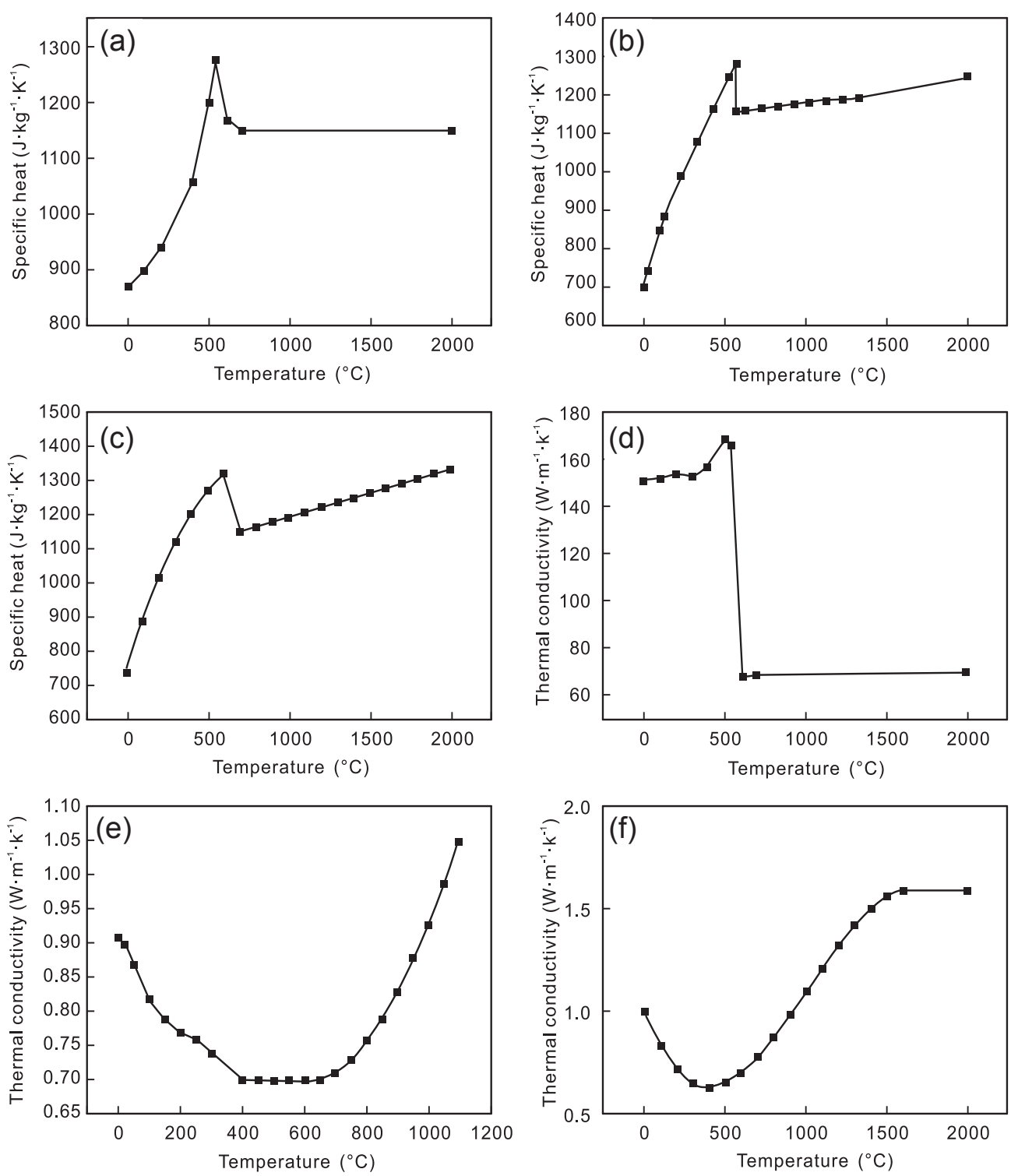

Fig. 2: Thermophysical parameters of aluminum, and organic and inorganic binder bonded sand molds:

(a) Al alloy - specific heat; (b) organic sand mold - specific heat; (c) inorganic sand mold - specific heat; (d) Al alloy - thermal conductivity; (e) organic sand mold - thermal conductivity; (f) inorganic sand mold - thermal conductivity

$$
f_{l}=\sum_{i=1}^{N_{t}} \sum_{j=1}^{N_{m}} \frac{1}{\sigma_{T}^{2}}\left[T_{i j}^{m}-T_{i j}^{c}\left(h^{v}\right)\right] \cdot X_{i j l}-\frac{1}{\sigma_{l}^{2}}\left(h_{l}^{v}-h_{l}^{0}\right)
$$

where $\delta_{l k}$ is the Coronel mark.

The HTC between the casting and the mold can be achieved by using inverse method. The detailed calculating processes are as follows:

(1) Record the temperature curves of castings and molds during the solidification process;

(2) Assume the initial HTC, $h^{0}=\left\{h_{1}^{0}, h_{2}^{0}, \cdots, h_{N_{h}}^{0}\right\}$, and set the maximum number of iterations $\mathrm{M}$;

(3) Achieve the temperature field of casting and mold, $T_{i j}^{c}(h)$, through numerical simulation;

(4) Calculate the sensitive coefficient, $X_{i j l}$, through Eq. (3);

(5) Calculate and achieve $\Delta h_{k}$ through Eqs. (5)-(7).

If $\left|\Delta h_{k} / h_{k}\right|<\varepsilon$, the calculating program will stop and output $h$. Otherwise, $h_{k}^{v+1}=h_{k}^{v}+\Delta h_{k}$, and the program will go back to step 3 and calculate again.

According to the correlative studies, when the temperature was above the liquidus or below the solidus, the HTC remained constant. It increased linearly when the temperature was between the liquidus and the solidus ${ }^{[9-10]}$. Thus, the 4-point HTC curve was set up with temperature change in MAGMA. After the calculation, four additional output values were generated as the standard of measurement between the simulation and the experiment. These are as follows:

- Delta gradient, which is the sum of the difference in the first deviation.

- Delta integral, which is the Riemann integral between the measured and the simulated curves.

- Delta maximum, which is the maximum vertical (y-direction) distance between the base points of the two curves.

- Delta quadratic, which is the sum of all square distances between each individual base point (coordinate) in the common interval of both curves. 


\section{Results and discussion}

\subsection{Measured temperature}

Figure 3 shows the temperature measurement results of the two kinds of sand castings. It can be seen that the temperature of the inorganic sand mold increased faster than the organic mold, and the temperature of the casting in the inorganic sand mold decreased faster than the casting in the organic sand mold. By observing the temperature of $\mathrm{TC} 1$, the temperature of both the inorganic and organic molds show a plateau due to the identical heat absorption and exothermic of the castings during this period. In addition, the temperature plateau of the casting in the organic sand mold is longer than that in the inorganic sand.

\subsection{Calculated HTC}

The HTC curves shown in Fig. 4 were generated automatically from MAGMA as optimal results. The HTC between the Al alloy and the organic sand mold changed from 300 to $700 \mathrm{~W} \cdot \mathrm{m}^{-2} \cdot \mathrm{K}^{-1}$ along with the solidus-liquidus. The HTC between the $\mathrm{Al}$ alloy and the inorganic sand mold changed from $1,000-1,800 \mathrm{~W} \cdot \mathrm{m}^{-2} \cdot \mathrm{K}^{-1}$ along with the solidus-liquidus. Heat transfer from the $\mathrm{Al}$ alloy to the inorganic sand mold presented a larger value than the organic sand mold. This phenomenon showed a good agreement with the temperature comparison between organic and inorganic sand molds.

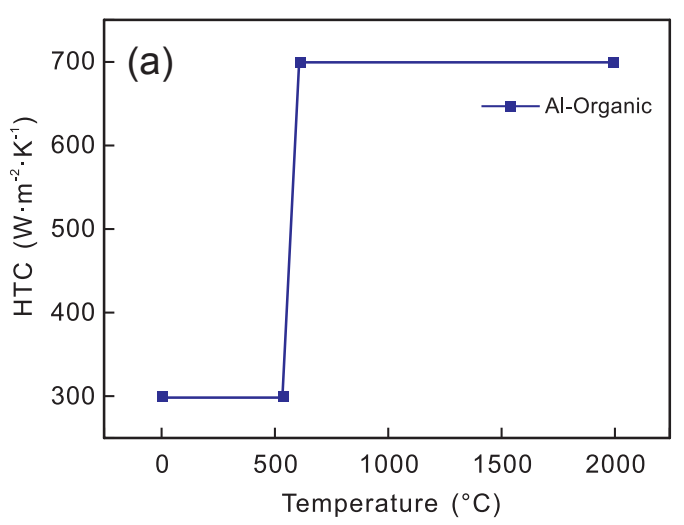

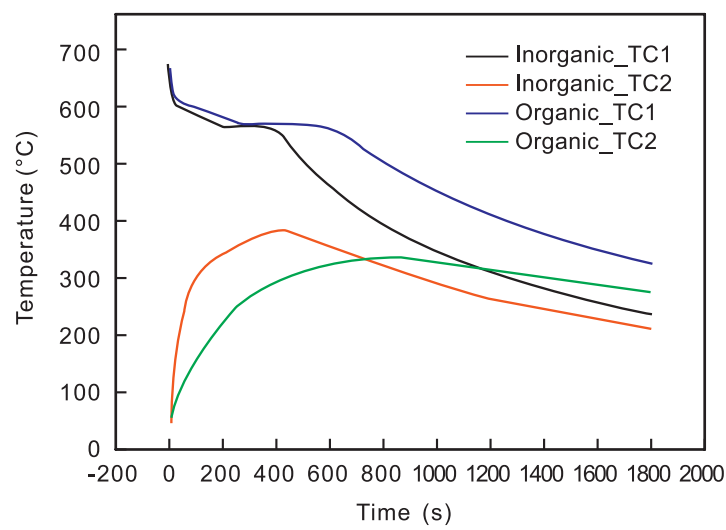

Fig. 3: Temperature curves of organic and inorganic sand casting

\subsection{Experimental verification}

Based on the inversed HTC, the solidification process of the organic and inorganic sand castings was calculated. Figure 5 shows the comparison of the simulated and measured temperatures during the solidification process. Both organic and inorganic sand castings showed the same trend of temperature change for both the simulation and the experiment. The maximum temperature deviation of the organic sand casting is $17.32{ }^{\circ} \mathrm{C}$, while that of the inorganic sand casting is $18.77^{\circ} \mathrm{C}$. Table 2 lists all the output values which are used to evaluate the difference between the simulation and the experiment.

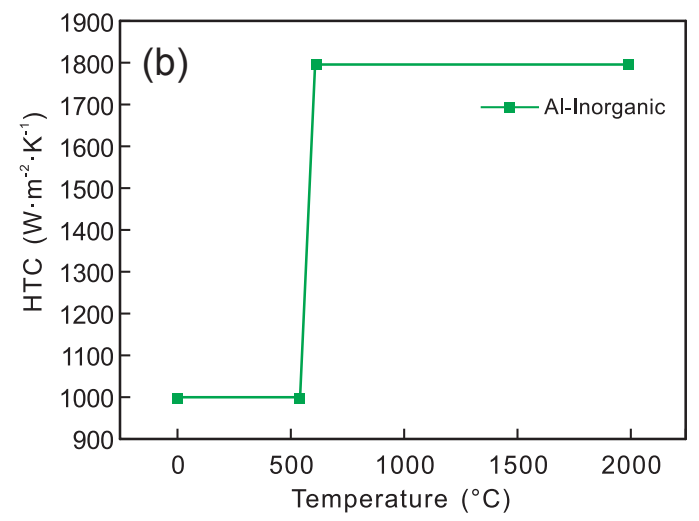

Fig. 4: Relationship of HTC with interface temperature for different sand molds: (a) Al-organic; (b) Al-inorganic
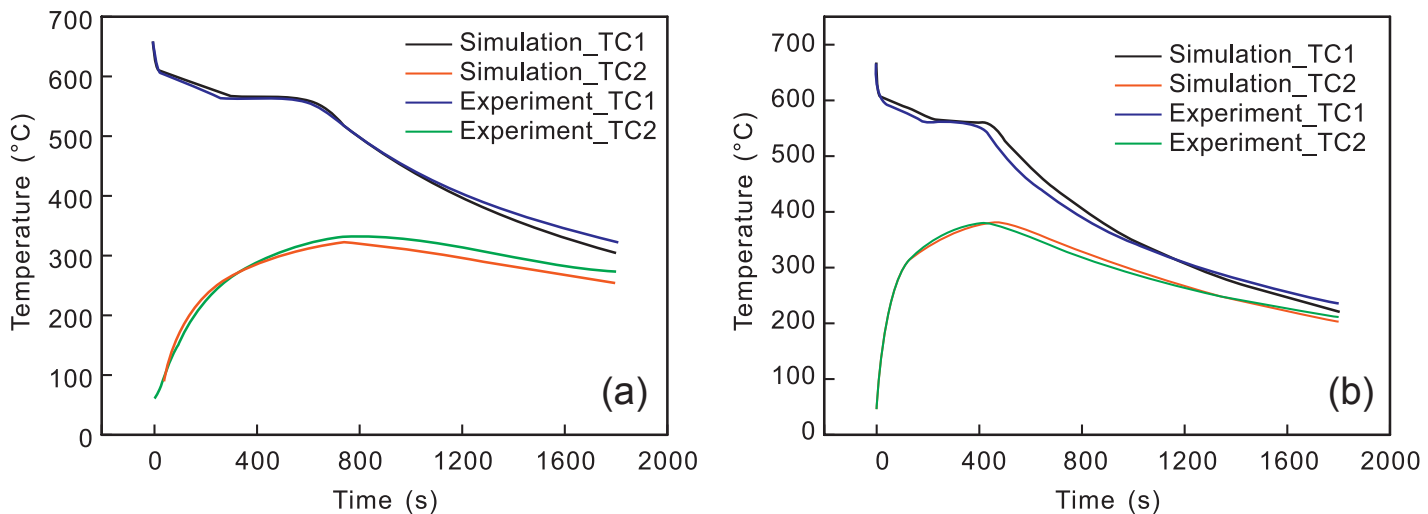

Fig. 5: Comparisons of simulated and experimental temperatures: (a) Organic sand casting; (b) Inorganic sand casting 
Table 2: Output values of inverse model from MAGMA

\begin{tabular}{ccccc} 
& Delta gradient & Delta integral & Delta maximum & Delta quadratic \\
\hline Organic sand_TC1 & 86.97 & 12936.16 & 16.43 & 783936.56 \\
Organic sand_TC2 & 89.29 & 25021.11 & 17.32 & 2211045.75 \\
Inorganic sand_TC1 & 117.97 & 17062.55 & 18.77 & 3310589.0 \\
Inorganic sand_TC2 & 86.53 & 11752.03 & 17.9 & 1433232.5
\end{tabular}

Figure 6 shows the shrinkage morphologies of the castings which showed a good correspondence with the simulation results. The shrink depth of the inorganic casting showed a deeper shape. In order to evaluate the cooling rates of the organic and inorganic sand castings, SDAS were measured from middle to the edge of the castings. The microstructure and SDAS values are shown in Fig. 7. The average SDAS values of the organic casting are 80.4, 64.3, and $52.9 \mu \mathrm{m}$ from the center to the edge, while those of the inorganic casting are 65.7, 51.4, and $45.9 \mu \mathrm{m}$, respectively. In summary, the SDAS values of the inorganic casting are lower than that of the organic casting. It is confirmed that the cooling rate of the inorganic casting is faster than the organic one.

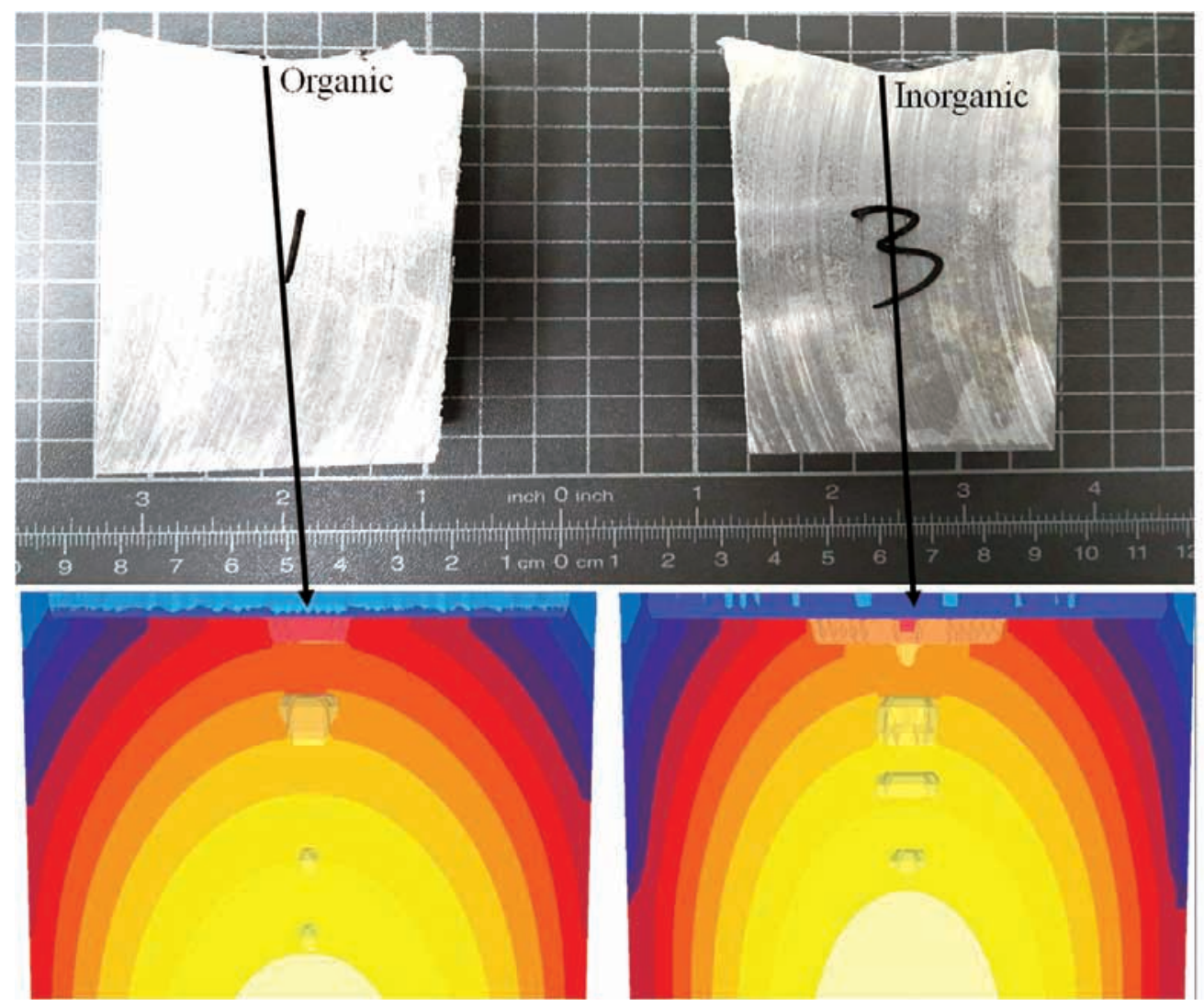

Fig. 6: Comparison of shrinkage morphologies for experimental and simulated castings

\section{Conclusions}

(1) During the solidification process, the temperature of the inorganic sand mold increases faster than that of the organic one. This can be explained by the greater thermal resistance of the organic sand mold.

(2) The optimal HTC between the Al alloy and the organic sand mold is confirmed to be 300 to $700 \mathrm{~W} \cdot \mathrm{m}^{-2} \cdot \mathrm{K}^{-1}$ along the solidus-liquidus. Meanwhile, 1000 to $1800 \mathrm{~W} \cdot \mathrm{m}^{-2} \cdot \mathrm{K}^{-1}$ was exported as the optimal HTC between the Al alloy and the inorganic sand mold.

(3) Both organic and inorganic sand castings show the same trend of temperature change for both the simulated and experimental results. Shrinkage morphologies of the castings show a good correspondence with the simulation results. SDAS measurement results proved that the cooling rate of the inorganic casting is faster than the organic casting. 


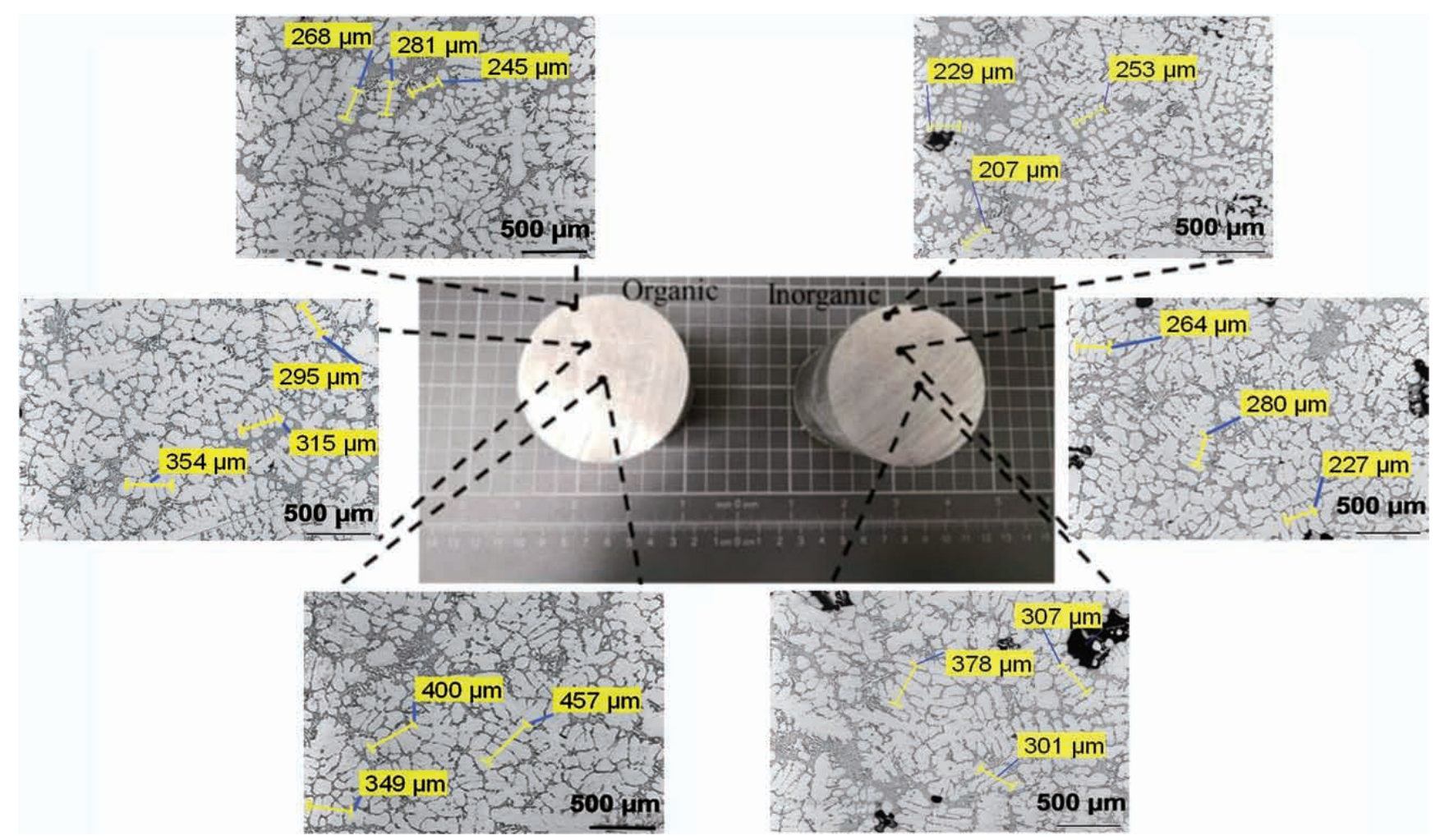

Fig. 7: Microstructures and SDAS of organic and inorganic sand castings

\section{References}

[1] Jiang W M, Fan Z T. Gating system optimization of low pressure casting $\mathrm{A} 356$ aluminum alloy intake manifold based on numerical simulation. China Foundry, 2014, 11(2): 119-124.

[2] Wu S P, Li C Y, Guo J J, et al. Numerical simulation and experimental investigation of two filling methods in vertical centrifugal casting. Transactions of Nonferrous Metals Society of China, 2006, 16(5): 1035-1040.

[3] Vijayaram T R, Sulaiman S, Hamouda A M S, et al. Numerical simulation of casting solidification in permanent metallic molds. Journal of Materials Processing Technology, 2006, 178: 29-33.

[4] Chen W L, Yang Y C, Lee H L. Inverse problem in determining convection heat transfer coefficient of an annular fin. Energy Conversion and Management, 2007, 48: 1081-1088.

[5] Kobryn P A, Semiatin S L. Determination of interface heattransfer coefficients for permanent-mold casting of Ti-6Al-4V. Metallurgical and Materials Transactions B, 2001, 32: 685-695.

[6] Sun Z Z, Hu H R, Niu X P. Determination of heat transfer coefficients by extrapolation and numerical inverse methods in squeeze casting of magnesium alloy AM60. Journal of Materials Processing Technology, 2011, 211: 1432-1440.
[7] Zhang A, Liang S, Guo Z, et al. Determination of the interfacial heat transfer coefficient at the metal-sand mold interface in low pressure sand casting. Experimental Thermal and Fluid Science, 2017, 88: 472-482.

[8] Sun J Y, Le Q C, Fu li, et al. Gas entrainment behavior of aluminum alloy engine crankcases during the low-pressure-diecasting process. Journal of Materials Processing Technology, 2019, 266: 274-282.

[9] Hamasaiid A, Dargusch M S, Davidson C J, et al. Effect of mold coating materials and thickness on heat transfer in permanent mold casting of aluminum alloys. Metallurgical and Materials Transactions A, 2007, 38: 1303-1316.

[10] Broucaret S, Michrafy A, Dour G. Heat transfer and thermomechanical stresses in a gravity casting die influence of process parameters. Journal of Materials Processing Technology, 2001, 110: 211-217. 